\title{
Ingleses e o Rio Capivari: forma urbana, espaços públicos, natureza e urbanidade
}

\author{
David Sadowski, Adriana Marques Rossetto*
}

Resumo O trabalho faz uma breve análise morfológica do distrito de Ingleses do Rio Vermelho, em Florianópolis, com preocupações específicas no tocante à sua relação com o meio ambiente e à qualidade dos espaços públicos formados, em um ambiente urbano densamente utilizado. Rechaça o oximoro cidade-natureza e ressalta a importância dos espaços públicos na vida em sociedade. Em relação ao recorte de estudo, lança mão da Teoria da Sintaxe espacial enquanto ferramenta de leitura espacial, a qual proporcionou, ainda, um melhor entendimento da dinâmica urbana do distrito, constituindo-se como poderosa ferramenta ao vislumbre de soluções locais alinhadas ao ideal de urbanidade.

Palavras-chave: forma urbana, meio ambiente, espaços públicos.

\section{Ingleses and the Capivari River: urban form, public spaces, nature and urbanity}

\begin{abstract}
This paper makes a brief morphological analysis of Ingleses do Rio Vermelho, Florianópolis, with specific concerns regarding its relation with the environment and the quality of the construction of public spaces, at a densely used urban environment. It rejects the oxymoron city-nature and emphasizes the importance of public spaces in society. Regarding the study cut-off, we use Spatial Syntax Theory as a spatial reading tool, which also provided a better understanding of the district's urban dynamics, constituting itself as a powerful tool for the glimpse of local solutions aligned with the ideal of urbanity.
\end{abstract}

Key words: urban form, environment, public spaces.

\section{Ingleses e el Rio Capivari: forma urbana, espacios públicos, naturaleza e urbanidad}

Resumen El presente trabajo hace un breve análisis morfológico de Ingleses del Río Vermelho, Florianópolis, con preocupaciones específicas en cuanto a su relación con el medio ambiente ya la calidad de los espacios públicos formados, en un ambiente urbano densamente utilizado. Rechaza el oximoro ciudad-naturaleza y resalta la importancia de los espacios públicos en la vida en sociedad. En cuanto al recorte de estudio, lanza mano de la Teoría de la Sintaxis espacial como herramienta de lectura espacial, la cual proporcionó, aún, un mejor entendimiento de la dinámica urbana del distrito, constituyéndose como poderosa herramienta al vislumbre de soluciones locales alineadas al ideal de urbanidad.

Palavras clave: forma urbana, medio ambiente, spacios públicos. 
*David Sadowski é Arquiteto e Urbanista, mestrando do Programa de Pós-Graduação em Urbanismo, História e Arquitetura da Cidade, da Universidade de Santa Catarina, ORCID: <http://orcid. org/0000-0002-7403-3177>. Adriana Marques Rossetto é Arquiteta e Urbanista, professora adjunta do Departamento de Arquitetura e Urbanismo da Universidade Federal de Santa Catarina, ORCID: <https://orcid. org/0000-0002-7785-9599>. rápido e recente crescimento das cidades litorâneas brasileiras, marcado por forte segregação sócio espacial e descaso com o meio ambiente, denota, mais claro do que nunca, a injustiça social e a insustentabilidade ambiental vivenciada pela nossa sociedade. A reversão desta realidade, premente e desafiadora, não pode ser debatida sem que haja locais públicos privilegiados para tamanha responsabilidade.

Tradicional palco de debates críticos, diálogos e interações entre classes, o espaço público tradicional sofre recente processo de esvaziamento: o habitat usual é substituído por formas de comunidades fechadas à grande maioria da sociedade. A hipervalorização da privacidade, intimidade, retraimento e silêncio -fenômenos contemporâneos-, marcam um processo de fragmentação do indivíduo e de sua atuação política (SENNET, 1999). Não bastasse todo esse distanciamento da esfera pública, o indivíduo também rompe com o meio ambiente. Estigmatizado como símbolo de atraso, como oposto daquilo que representa o ideal de cidade, o meio ambiente e corpos d'água passam a ser desvalorizado, tratados como subproduto urbano.

A cidade contemporânea opera esses desequilíbrios socioambientais enormes. O conceito de urbanidade, entretanto, desponta surge, como contracorrente desta tendência. A urbanidade, entendida por Mello (2008) como aquilo que qualifica a vida urbana através da possibilidade indiscriminada de utilização dos espaços públicos, do desenvolvimento cultural por meio da interação social entre diferentes e da relação harmônica entre as pessoas e o meio vem despontando como ideal recorrente no discurso e atuação de importantes profissionais preocupados com a urbe.

Não devemos, portanto, cair na armadilha de encarar a urbanidade enquanto conceito necessariamente ligado à artificialidade e, consequentemente, como antítese de preservação. Defendemos que urbanidade e preservação não significam coisas dissonantes, mas complementares: estruturas naturais inseridas no meio urbano e utilizadas sustentavelmente provocariam o sentimento de pertença por parte da população, levando a sua preservação.

O espaço urbano, misto de cidade e natureza, é dado concreto. Como tal, apresenta contornos próprios que o definem, que Ihe conferem uma forma urbana. Determinado por condicionantes sócio naturais do ambiente em que se insere, a forma urbana, uma vez pronta, é capaz de influenciar diretamente a sociedade sob diferentes aspectos. Em meio a essa multiplicidade de aspectos, também chamados de dimensões, evidenciamos aquele diretamente ligado aos limites e possibilidades que a configuração dos espaços, em especial os públicos, impõe aos encontros, esquivanças à e visibilidade do outro: o aspecto sociológico.

Segundo a teoria da Sintaxe Espacial, cunhada por Hillier, um espaço público fluido e integrado propicia valorosas interações pessoais, condição necessária, defende Sennet (1999), ao crescimento pessoal. Sobre o assunto, Peponis evidencia, ainda, que se 
"a sociedade enquadra as pessoas em diferentes classes, papéis e posições, o espaço urbano pode ser um dos meios de reintegração" (PEPONIS,1989, p. 23).

Situado no extremo norte da llha de Santa Catarina, o Distrito de Ingleses de Rio Vermelho aponta para uma forte dinâmica de crescimento, com aumento populacional acima das médias locais, que provocaram intensas transformações sócio espaciais. A premência de soluções que coloquem a natureza em primeiro plano e que busquem um ambiente urbano densamente utilizado, estabelece as preocupações chave deste trabalho. Posto isso, o presente trabalho tem como objetivo analisar a relação entre a forma urbana de Ingleses e a apropriação social de seus diferentes espaços públicos e interfaces estabelecidas com seus espaços naturais, em especial o Rio Capivari. Em seguida, importa especular o potencial protetor e articulador de um possível parque linear ao longo do referido corpo d'água.

\section{Forma urbana, natureza e cidade}

O oximoro cidade-natureza dá o tom das expansões das cidades no mundo. Mello (2008) defende que há tempos a tradição vem colocando cidade natureza em campos opostos, fato este que continua a afetar a maneira como as urbanizações acontecem. A autora explica que a busca de um sonho de modernidade urbano provocou um recente fenômeno de abandono rural. Esse processo, via de regra, foi marcado por um paradigma de ruptura, de renegar tudo relacionado à vida no campo, estigma de "atraso". A estrutura da cidade emerge, assim, dissociada dos valores físico-ambientais de onde está inserida.

O intenso crescimento porque passaram as cidades contemporâneas despertou uma preocupação mundial acerca dos recursos naturais não renováveis, impactos sobre as estruturas naturais e destinos do planeta. A incapacidade do meio em lidar com os constantes desequilíbrios, aliados a uma visão de finitude deste alicerçam o conceito de sustentabilidade, para o qual importam três fundamentos: conservação dos sistemas ecológicos; garantia de sustentabilidade dos recursos renováveis; e manutenção das ações humanas dentro da capacidade de carga dos ecossistemas (FRANCO, 2001, p.26). É interessante observar que o conceito do desenvolvimento sustentável não exclui a convivência com o fenômeno urbano. Pelo contrário, passa a incluir aspectos urbanísticos, numa busca por um "caminho do meio".

No litoral brasileiro, no entanto, prevalecem as atitudes individualistas: ao passo que todos almejam a preservação ambiental, muitos sequer percebem que contribuem para a manutenção de um modelo perverso, onde a adição continuada e extensiva de casas soltas no lote dá o tom das expansões (MITTMANN, 2008, pg. 15). Em concordância com Macedo, os ecossistemas costeiros são muito sensíveis, não suportam ocupações intensivas e "não podem ser reduzidos a partes dissociadas entre si, sem que ocorra uma perda significativa de suas características" (MACEDO, 2004, p. 59). Definitivamente, as vantagens e desvantagens dos modelos de ocupação devem urgentemente entrar na pauta dos debates preocupados com a sustentabilidade ambiental.

Sob o ponto de vista arquitetônico-urbanístico, além do interesse no que tange às questões de preservação, importa compreender os efeitos que a espacialização do fenômeno urbano desempenha por sobre a sociedade. O enlace entre cidade e 
natureza é dado concreto. Como tal, apresenta uma forma que o define e, uma vez pronta, além dos impactos na natureza, a forma urbana influencia diretamente as dinâmicas sociais.

Segundo Sennet (1993) e Peponis (1991), a forma dos espaços públicos permite o reconhecimento mútuo dos usuários, servindo como base de sustentação do modo de vida de diferentes grupos, relacionando diferentes ideias, discursos e identidades culturais.

O comportamento "público" é, antes de tudo, uma questão de agir a certa distância do eu, de sua história imediata, de suas circunstâncias e de suas necessidades; em segunda lugar, essa ação implica a experiência da diversidade (SENNET, 1993, p. 115). Coisas e pessoas que são estranhas podem perturbar ideias familiares e verdades estabelecidas; o terreno não familiar tem uma função positiva na vida do ser humano (SENNET, 1993, p.359).

Hillier e Hanson (1994), por meio da Lógica Social do Espaço e da Sintaxe Espacial, são pioneiros em defender a correlação entre diferentes formas de reprodução social e distintas ordens espaciais. Para tanto, encaram a cidade como grande arranjo de barreiras e permeabilidades hierarquizadas. É importante salientar que esses autores, cujos princípios e conceitos são base este trabalho, não adotam uma postura determinista da forma urbana, mas relacional

A forma espacial cria um campo de encontros e copresenças possíveis (embora nem todos realizáveis), dentro do qual vivemos e nos movemos e, ainda que isto não leve à interação social, este campo é em si mesmo um recurso sociológico e psicológico importante (HILLIER, 1986, p.12).

Tal maneira de encarar a forma urbana, explica Peponis (1992) explica que a Sintaxe Espacial revela uma evolução no estudo da forma urbana, uma vez que passa a encarar o assunto sob os pontos de vista local e global. Importante perceber, ainda, que tais estudos contribuem para a quebra definitiva da

orientação funcionalista que reconduzia sempre aos sistemas de movimento ou ao zoneamento das atividades. o estudo renovado e insistente da forma construída nas cidades permitiu comprovar a eficácia do método morfológico, voltado a apresentar as partes da cidade como peças de um quebra-cabeças de múltiplas faces (SOLÁ-MORALES, 1986, p.9 e 10).

A Sintaxe Espacial tradicionalmente opera em duas instâncias analíticas complementares: a global e a local.

Acerca da instância global, dentre as diversas medidas sintáticas, deve-se chamar a atenção para uma em especial: a integração. Podemos dizer que a integração de um logradouro, ou a posição de um espaço em relação a todos os outros espaços do recorte urbano em estudo, é dos principais determinantes da quantidade de pedestres que passam por ele. Hillier et al (1993) defende que a configuração da malha, por si só, já incita grande dinâmica de movimento na cidade, sendo este movimento responsável pela definição de outros elementos do sistema urbano, como por exemplo o uso do 
solo e as densidades edilícias. Ora, se formos pensar que, por exemplo, comércios e serviços dependem de movimento para existirem, a constatação do autor se faz perfeitamente compreensível.

No que tange à instância local, segundo Alexander et al (1977), espaços pequenos e bem definidos tendem a ser densamente utilizados. E arrematam sugerindo que tais espaços promoveriam um grande sentimento de segurança. Espaços menores, defende Holanda, "têm sido historicamente identificados com a utilização secular" (HOLANDA, 2002, p.100), do dia-a-dia, sendo, portanto, desejáveis. Mas a qualidade morfológica de um espaço convexo não se restringe à sua delimitação e tamanho: é preciso que a massa edificada se comunique com os vazios. Nos dizeres de Holanda,

a literatura sintática tem denominado tradicionalmente essas transições de constituições, e diz-se de um espaço que ele é intensamente constituído quando, ao caminharmos por ele, passamos frequentemente defronte de transições para espaços fechados (Holanda, 2002, p. 98).

Os espaços cegos, ou ausentes de constituições, são indesejáveis para a vida pública. Significam que a massa edificada não se abre para as ruas e praças e, por conseguinte, não os alimentam com o trânsito de pessoas ou a oferta de serviços.

A facilidade com que a forma urbana propicia intensas apropriações de seus espaços públicos, ou seja, com sua capacidade de prover urbanidade, relaciona-se diretamente com a sustentabilidade urbanística (ACSELRAD, 2001). Não devemos, no entanto, cair na armadilha de encarar a urbanidade enquanto conceito necessariamente ligado à artificialidade e, portanto, como antítese de preservação.

A ideia de que urbanidade é equivalente à construção concentrada ou à ausência de árvores e jardins é baseada num limitado conhecimento das cidades, ou numa limitada definição de urbanidade (MUNFORD, 1998 apud MELLO, 2004, p. 4).

Defendemos que urbanidade e preservação não significam coisas dissonantes. Pelo contrário, além de estarem relacionadas à forma urbana, acreditamos que espaços densamente utilizados e em contato com a natureza suscitariam, inclusive, a proteção ambiental. Explicamos: de acordo com Mello (2008), o princípio da intangibilidade conduz à desvalorização e degradação do meio ambiente, ao propugnar o afastamento das pessoas, impedindo o contato com a natureza. Por outro lado, espaços sensíveis utilizados de maneira sustentável e prenhes de urbanidade promoveriam o sentido de pertença por parte da população. Assim, a abordagem dos espaços ambientalmente sensíveis segundo a ótica da urbanidade se apresenta, em última instância, como estratégia de proteção dos recursos ambientais. Além disso, entendemos que o contato constante das pessoas com meio permite uma vigília permanente, fato que torna muito mais difícil qualquer tipo de ação que venha a prejudicar a natureza.

Essa reflexão, conforme sugere Mello (2008), implementa o conceito de urbanidade defendido em nossa pesquisa. A urbanidade passa a ser entendida enquanto conjunto de atributos da forma que qualificam a vida urbana através da possibilidade indiscriminada de apropriação dos espaços públicos, do desenvolvimento cultural e da interação harmônica entre as pessoas e o meio. 
A capacidade de impactar o meio, assim como "de impor um leque de alternativas limitadas às aspirações e necessidades da população e de restringir as opções de ação" (SANTOS,1985) revela a importância de lidar com a forma urbana.

\section{Metodologia}

Essencialmente, a proposta de pesquisa exigiu a compreensão de dois temas: Forma Urbana e Natureza e Forma Urbana e Sociedade.

Sobre o tema Forma Urbana e Natureza, parte-se da compreensão da natureza como elemento partícipe e qualificador da vida urbana. Abordagens integradas, proponentes de modelos de espaços urbanos mais conectados ao meio dão o tom das reflexões.

Acerca do segundo tema, foi estudada, de forma direta ou implícita, a importância da forma urbana no que tange às práticas e vivências dos distintos grupos sociais.

Para o estudo dos efeitos sociais da forma urbana em Ingleses, lançamos mão da Teoria da Sintaxe Espacial, desenvolvida por Hillier (1984).

De modo a analisar brevemente o desempenho dos espaços públicos do distrito alvo de estudo, utilizamos as duas dimensões sintáticas de análise propostas por Hollanda (2002): dimensão global -relativa à totalidade do recorte de estudo, atentando para as características de articulação de toda a rede de espaços públicos- e dimensão local - relacionada a um trecho distinto de uma rua ou praça.

Na análise global, lançamos mão da técnica sintática da axialidade. Para tanto, utilizamos como base um mapa de linhas axiais do local, que nada mais é do que o conjunto do menor número de maiores linhas possível que cruzam a totalidade dos espaços públicos abertos. Dentro do ambiente do software Depht Map, o mapa das linhas axiais nos permite saber, através de uma relação de interdependência de cada linha em relação ao todo, quais as vias mais integradas (mais próximas do vermelho) e aquelas mais segregadas (mais próximas do azul). Na análise local, examinamos a maneira como as edificações se relacionam com os espaços públicos por meio de suas constituições e delimitações.

Por fim, a vitalidade dos espaços será medida, indiretamente, através da aferição dos usos edilícios, para em seguida ser confrontada com os logradouros mais integrados.

\section{Caracterização da área}

Localizado no extremo norte da ilha, Ingleses é delimitado a norte e a Leste pelo mar; a oeste pelo Morro da Feiticeira e do Bom Jesus; e a sul pelo Distrito do Rio vermelho. Vítima de um intenso crescimento, ocorrido, sobretudo, nas últimas décadas, o distrito estudado (Figura 1) denota duas realidades distintas: ao mesmo tempo em que existe um típico balneário turístico, alvo de pesados investimentos de qualificação urbana e bastante procurado por turistas e veranistas, outra parte de Ingleses assume os ares de cidade periférica. Podemos dizer, grosso modo, que a rodovia que dá acesso ao distrito - Rodovia SC 403- serve como divisor de águas: ao norte da supracitada via, e mais próximo ao mar, temos a cidade formal, fortificada em seus condomínios e 
Figura 1: Ingleses e a llha de Florianópolis. Fonte: elaborado pelos autores. prédios. A cidade informal, por sua vez, encontra-se ao sul da SC e, portanto, mais distante do mar. Reflexo deste panorama, nota-se que, apesar da ordem observada em Ingleses Norte, "O distrito de Ingleses, inclusive é um dos que apresenta maior carência de infraestruturas e um intenso crescimento populacional" SUGAI (2002). É interessante notar como a localidade local sofre duplamente os efeitos das disputas pelo solo: em nível intra e interbairros.

O espaço urbano resultante do rápido crescimento de um distrito há pouco basicamente rural, aliado à falta de fiscalização, planejamentos condizentes e desconhecimentos diversos fazem-se sentir na atual configuração do seu tecido urbano e na sua relação com a paisagem local. Vias de até mil metros sem conexões intermediárias, condomínios e loteamentos desarticulados do restante da malha, escassez de espaços públicos interessantes, degradação de áreas ambientalmente sensíveis, grandes áreas com usos pouco diversificado, insegurança generalizada são alguns dos problemas vivenciados pela população local - Problemas e excessos estes observados, também, na porção mais abastada da localidade.
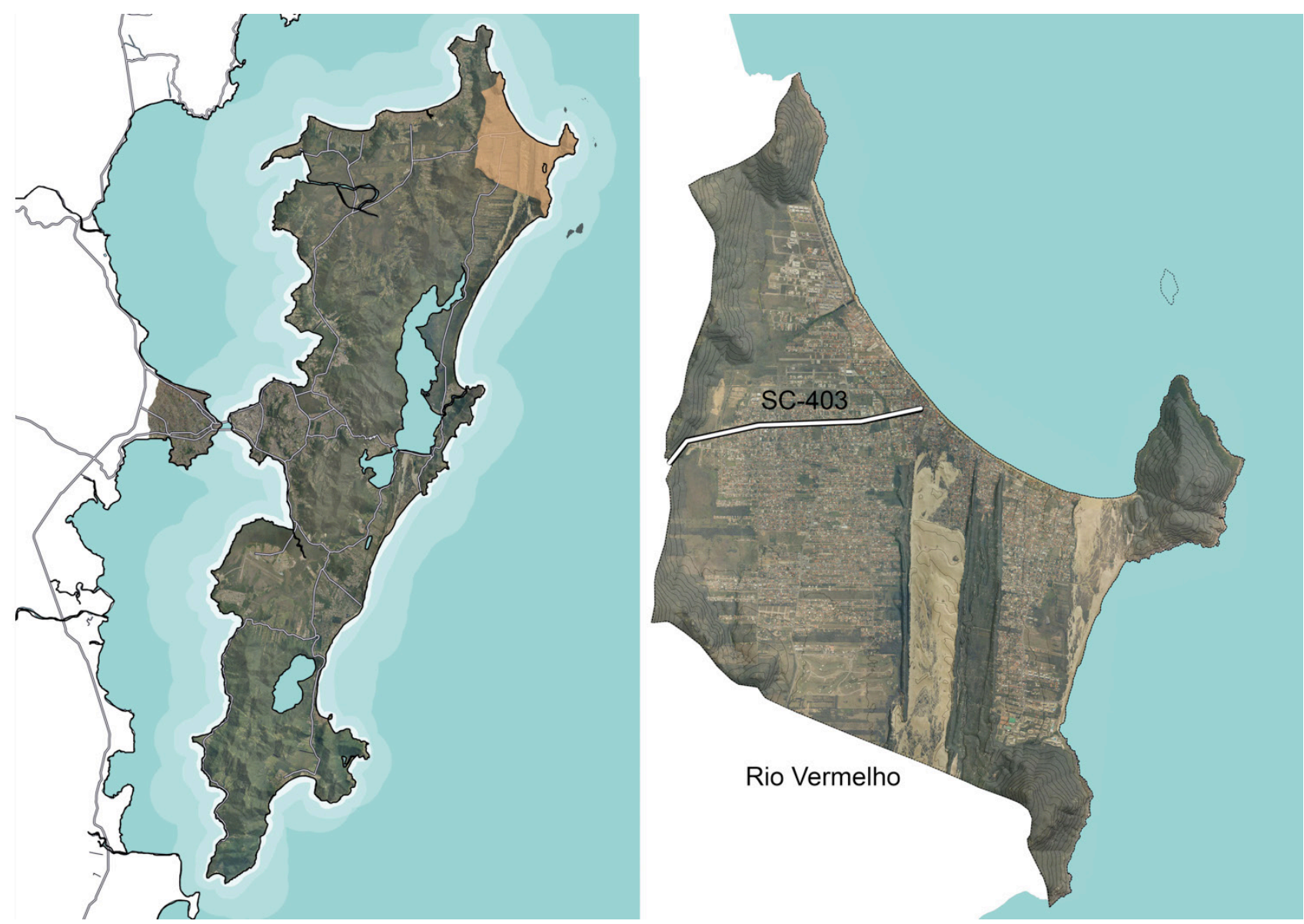

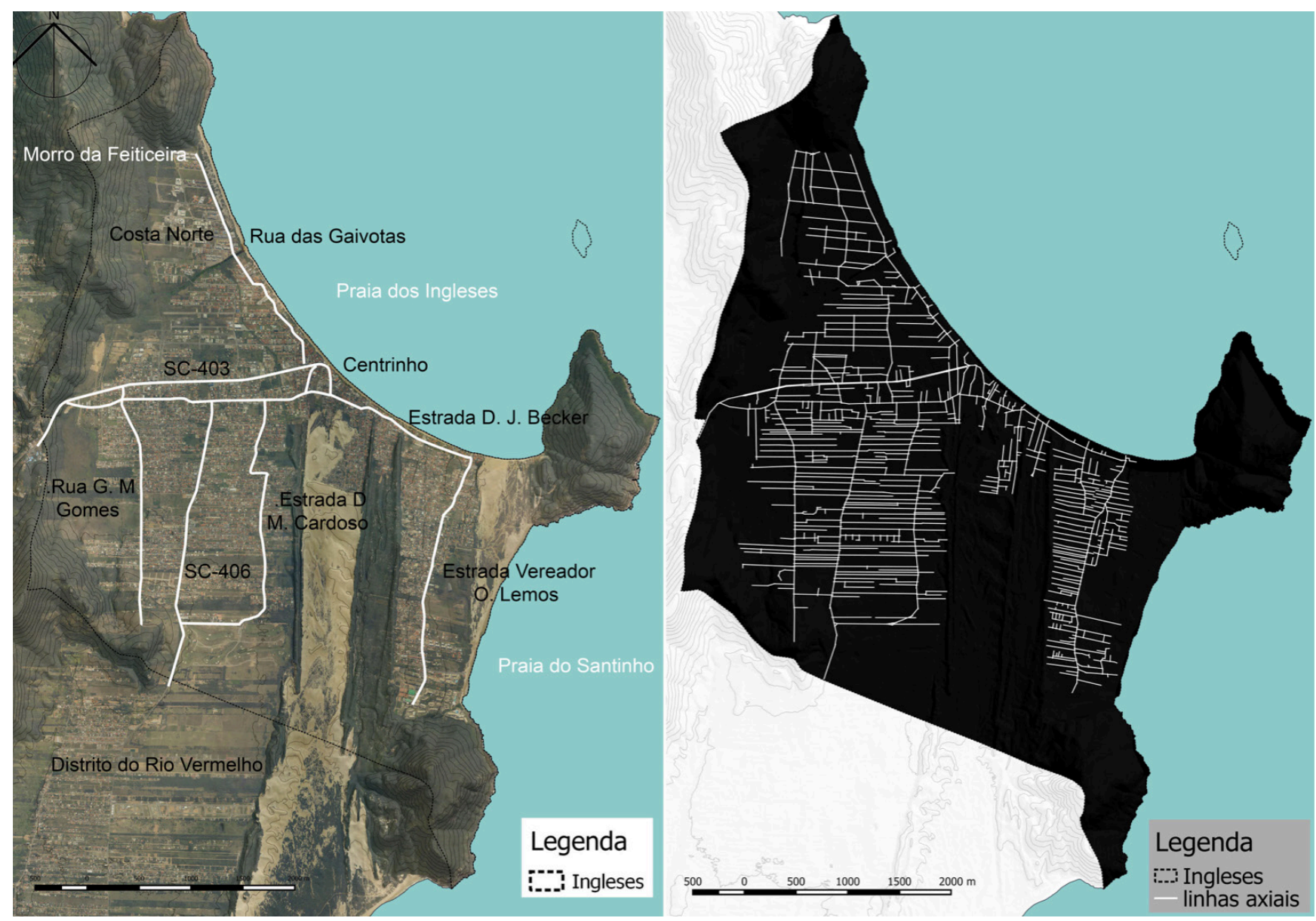

Figura 2: à esquerda, o distrito de Ingleses; à direita, o mapa axial local. Fonte: elaborado pelos autores.

\section{Resultados e discussão}

A análise das proximidades da principal via de acesso ao distrito (Figura 2), a SC-403, bem como das demais vias estruturantes da porção sul do bairro (SC-406, Rua G. Manoel Gomes e Estrada D. Manoel Cardoso), revela a clara presença de um núcleo integrador (Figura 2). Chama-se atenção, também, para a forte integração observada no chamado "centrinho" do bairro.

A forte concentração de linhas mais integradas em porções próximas às vias principais de acesso pode ser explicada pelo modelo de ocupação característica de Florianópolis. As estruturas territoriais preexistentes, baseadas fortemente no parcelamento rural da terra, desenvolviam-se através de estreitas, porém profundas, faixas perpendiculares à praia e às vias estruturantes, com estrutura formal condicionada pela topografia e por ecossistemas naturais da região. Com o decorrer do tempo, ruas perpendiculares às vias principais eram abertas e, com elas, sucessivos desmembramentos "fatiavam" as grandes glebas rurais. Via de regra, estes diferentes desmembramentos não se comunicavam diretamente, numa prática onde as ruas que davam acesso aos diversos lotes desmembrados desembocavam diretamente nas grandes e pretéritas vias. Esse 
padrão de ocupação, sem travessas entre os lotes desmembrados, refletem um processo de crescimento carente de planejamento e pouco articulado entre si.

Destaque-se a notável segregação observada na Praia do Santinho, mesmo em sua via estruturante. Tal fato se dá muito em função de suas características peculiares de localização: o bairro se constitui um "fim de linha", possuindo somente uma entrada. Semelhante apartação pode ser percebida em Ingleses Norte, sobretudo acima do Rio Capivari, nos domínios do projeto de conjunto conhecido como Costa Norte, local onde predominam os condomínios verticais fechados, extremamente exclusivos e pautados nas ideias de intimidade, segurança e conforto.

Em concordância com a análise global, a investigação local revela que quanto mais integrados, maior a tendência à existência de logradouros de pequena escala, bem definidos e bastante constituídos. A exceção fica por conta da SC-403, mas somente no que se refere à dimensão local: ainda que bem definido e constituído, o local é muito mais amplo do que as demais estradas gerais. Destaque-se as características locais do "centrinho de Ingleses", espaço mais constituído e bem definido do recorte de estudo. As diversas servidões, e em especial a região do projeto Costa Norte, tendem a se apartar da rua por muros e grades. Na região Norte, contudo, há o agravante da grande escala das ruas, rótulas e praças locais (Figura 4).

É de nosso conhecimento, devido à nossa vivência no local, que as citadas ruas estruturantes são, sim, as maiores concentradoras de diferentes usos e fluxos (o que pode ser confirmado, indiretamente, pelo mapa de usos, vide Figura 3). É sabido, também, como corolário da lógica instalada nos domínios do Costa Norte, que a rua como espaço público, sobrevalorizada, passa a servir, quando muito, ao simples deslocamento de residentes entre diferentes áreas especializadas e a praia, percursos estes que muitas vezes são realizados através de automóveis. A presente discussão não possui, todavia, o fôlego nem a pretensão de confirmar, rua por rua, se de fato os locais mais integrados são os espaços de maior urbanidade. O que pretendemos, no entanto, além de demostrar os diferentes níveis sintáticos de integração hoje postos e afirmar que, de uma forma geral, os espaços mais integrados coincidem com os de maior urbanidade, é de chamar atenção para o potencial de urbanidade representado pelo Rio Capivari.

O Rio Capivari é, para a surpresa de muitos, um rio que atravessa boa parte de Ingleses. Nascendo no lado Noroeste do distrito, mais precisamente no Morro da Feiticeira, o rio desenha seu formato num percurso bastante variado: por um lado, margeia quase a totalidade do Morro da Feiticeira, até morrer na SC-403; por outro, inicia seu trajeto derivando no primeiro veio e cortando o setor Norte da praia no sentido Oeste-Leste, para em seguida rasgar o bairro, em uma posição bastante central, no sentido Norte-Sul e, enfim, terminar a Sudeste como um ribeirão que tangencia as dunas limítrofes à Praia do Santinho (ver Figura 5).

No caso de Ingleses, assim como acontece com as diversas estruturas naturais locais (outrora dominantes por toda a planície, dunas, brejos e morros), constantemente arrasadas e desprezadas, ignoram-se os aspectos ambientais e o potencial urbano representado pelo Rio Capivari, elemento recorrente nos fundos de lote privativos. $\mathrm{O}$ que fizemos, entretanto, foi assumir o espaço como possível componente da malha urbana, simulando, para tanto, um parque linear ao longo de seu leito (Figura 4). 

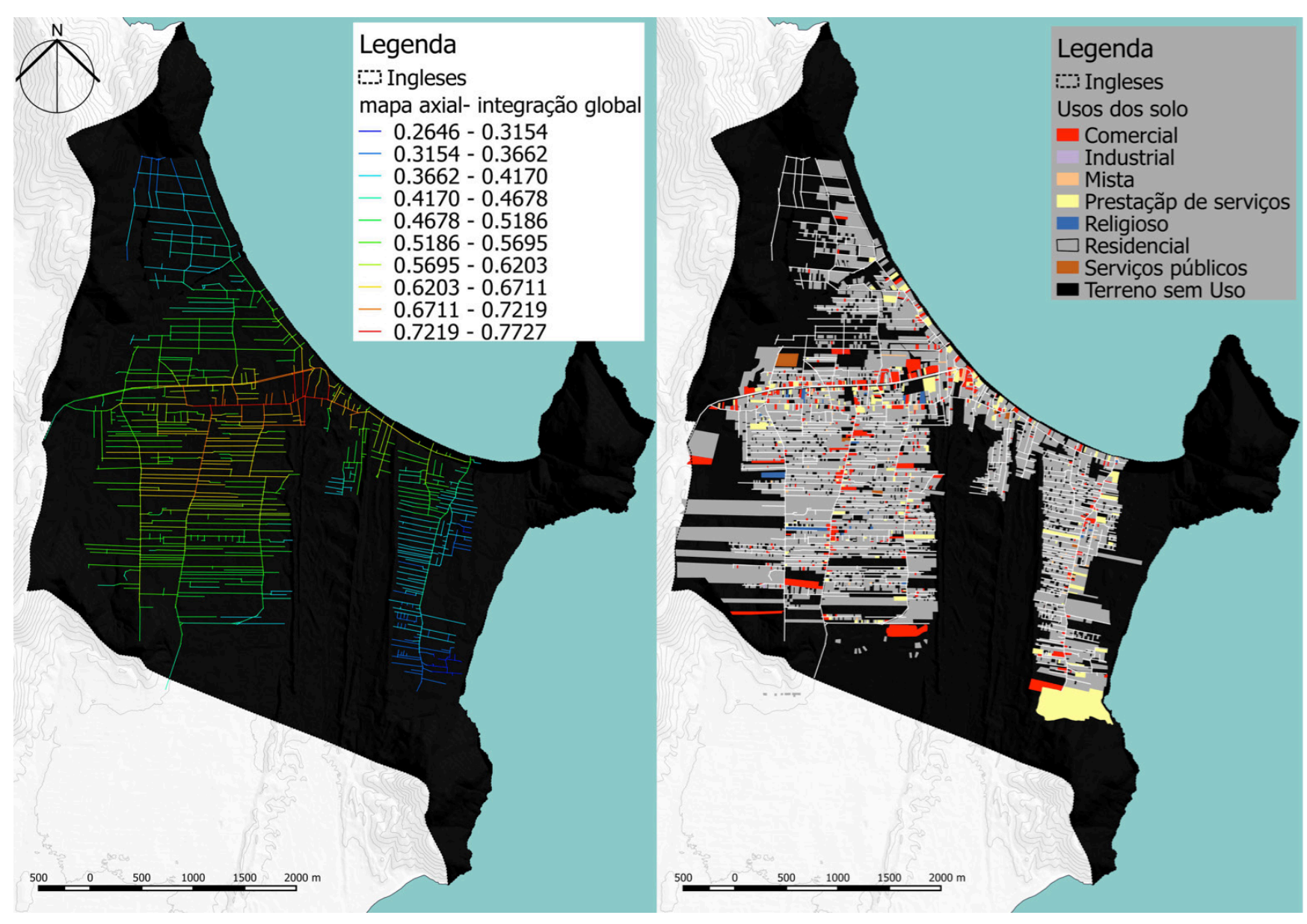

Figura 3 (topo): à esquerda, a análise global de integração local; à direita, os usos edilícios locais. Fonte: elaborado pelos autores. 


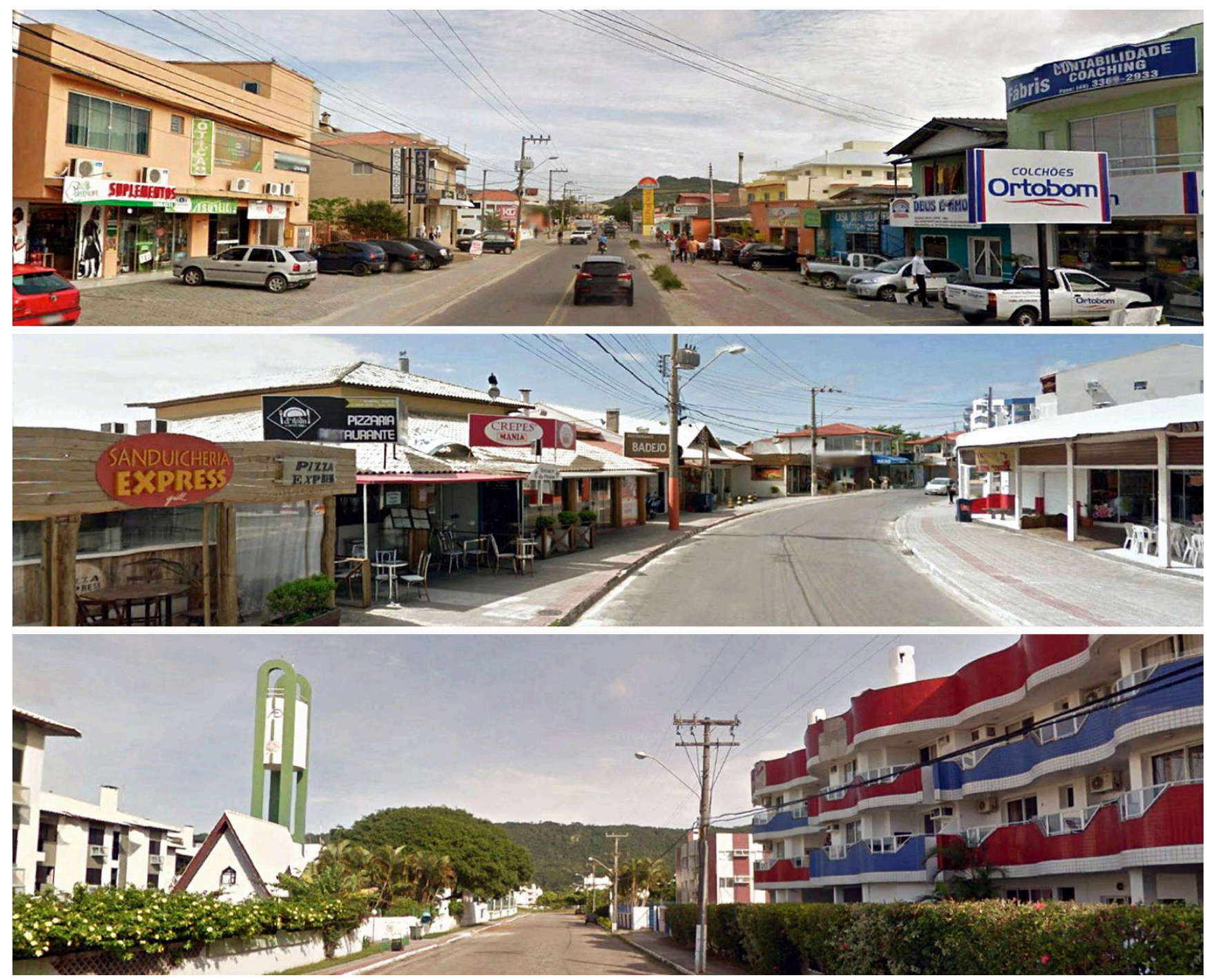

Figura 4: em cima, típica estrada geral; no meio, centrinho de Ingleses; embaixo, rua do Costa Norte. 

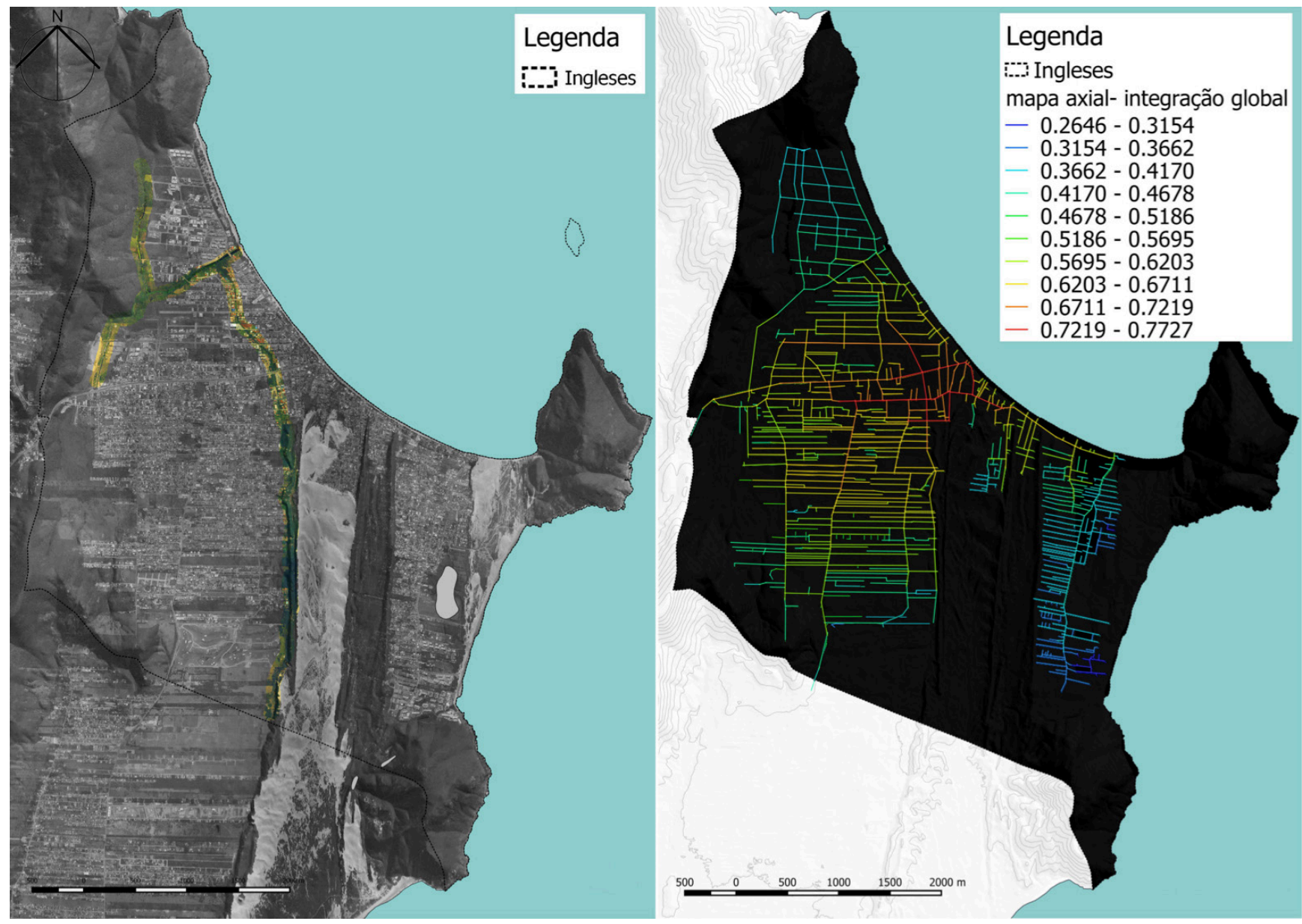

Figura 5: à direita, o Rio Capivari em destaque; à esquerda, o mapa de integração local considerando o Rio Capivari. Fonte: elaborado pelos autores.
Para nossa surpresa, o resultado desta proposta, segundo a Teoria da Sintaxe Espacial, é surpreendentemente bom: sua posição bastante central caracteriza-o como potencial eixo de integração para o local. Além de altos valores de integração global, o parque proposto irradia sua integração, incrementando os valores das vias no seu entorno em até 30\%, sobretudo naquelas mais próximas à SC.

O aumento da integração local, proporcionada por intervenções como o parque Rio Capivari, aliada a incentivos que revertem sua condição de fundos (fachadas contínuas, bem definidas e abertas para o corpo d'água) pode representar implemento importante para o aumento de vitalidade dos espaços públicos locais. Usos como comércios e serviços, essenciais na promoção de vitalidade, dependem do movimento para se sustentarem e, portanto, tendem a se localizar em localidades mais facilmente apropriáveis, numa relação dialética onde o movimento proporcionado pelas configurações morfológicas do local favorece a instalação de um mix de usos, que, por sua vez, atraem mais pessoas. Esse processo de retroalimentação, onde movimento gera diversidade, que 
gera movimento, pode ajudar a criar, em Ingleses, locais mais dinâmicos, seguros e interessantes. O protagonismo e dependência em relação aos principais eixos de ligação do bairro (aqueles mais integrados), pode ser, portanto, diluída, diminuindo a especialização das diferentes áreas, aumentando a heterogeneidade e reforçando a importância do restante da malha como espaço de vivências. De quebra, publicizar o leito do rio, integrando-o a malha urbana do distrito, despertaria, conforme defendemos, um maior cuidado para com o meio ambiente local.

\section{Considerações finais}

A busca por uma sociedade mais justa e ambientalmente sustentável depende de uma infinidade de fatores. Sobre o tema, salientamos o importante papel desempenhado pela forma dos espaços urbanos, sobretudo os públicos. Diretamente relacionada aos impactos por sobre a natureza preexistente, a formatação dada de uma rede local de espaços públicos também influencia diretamente a sociedade sob diferentes aspectos, dos quais chamamos atenção para o sociológico, bem como pode agir diretamente na relação que se estabelece com o meio ambiente. Lançar mão de ferramentas que nos proporcionem um melhor entendimento da dinâmica urbana representa estratégia essencial ao vislumbre de soluções alinhadas ao ideal de urbanidade. Nesse sentido, valiosos indícios acerca do desempenho dos espaços públicos podem ser obtidos pelas análises sintáticas, devendo atentar, porém, para a complementariedade de outras investigações.

\section{Referências bibliográficas}

HILLIER, Bill; HANSON, Julienne. The Social Logic of Space. Cambridge: Cambridge University Press, 1984

HILLIER, Bill; PENN, Alan; HANSON, Julienne; GRAJEWSKI, T.; XU, J. Natural movement. or, configuration and attraction in urban pedestrian movement. Environment and Planning B: Planning and Design, v. 20, n. 1, p. $29-66,1993$.

FRANCO, Maria de Assunção Ribeiro. Planejamento ambiental para a cidade sustentável. 2. ed. São Paulo: Annablume: Fapesp, 2001. 296 p.

MACEDO, Silvio. Paisagem, litoral e formas de urbanização. In: PROJETO ORLA: Fundamentos para gestão integrada. Brasília: MMA/SQA; Brasília: MP/SPU, 2004. p. 43-62.

MELLO, Sandra S. Na beira do rio tem uma cidade: urbanidade e valorização dos corpos d'água. Tese de Doutorado em Arquitetura e Urbanismo. Programa de Pesquisa e Pós-graduação, PPG/FAU, UNB

MITTMANN, Michel de Andrado. Uma cidade na areia: Diretrizes urbano-ambientais para a planície do Campeche. Dissertação de Mestrado. 0018-D. PGAU-Cidade (Programa de Pós Graduação em Urbanismo, História e Arquitetura da Cidade). UFSC. Dez.2008.

PEPONIS, John. Espaço, Cultura e Desenho Urbano no Modernismo Tardio e Além Dele. In: Boletim do IAU, Brasília, UnB, no. 51, 1991.

SENNETT, Richard. O Declínio do Homem Público: as tiranias da intimidade. São Paulo: Companhia das Letras, 1999.

SOLÁ-MORALES. Manuel de. Las formas de crecimiento urbano. Barcelona: Edicions UPC, Barcelona, 1993. 